\title{
Molecular characterization and evaluation of the emerging antibiotic-resistant Streptococcus pyogenes from eastern India
}

\author{
Dipanwita Ray ${ }^{1 *}$, Somnath Saha ${ }^{3}$, Sukanta Sinha ${ }^{4}$, Nishith Kumar Pal ${ }^{3}$ and Basudev Bhattacharya ${ }^{1,2^{*}}$
}

\begin{abstract}
Background: Group A Streptococcus strains causing wide variety of diseases, recently became noticeable in eastern India, are not amenable to standard treatment protocol thus enhancing the possibility of disease morbidity by becoming antibiotic resistance.

Methods: The association of Lancefield group A Streptococcal variation with degree of vir architectural diversity was evaluated using emm typing and restriction fragment length polymorphism analyses. The antibiotic sensitivity patterns were examined by modified Kirby-Bauer method of disk diffusion. Percentage calculations, 95\% confidence interval and one-way ANOVA were used to assess differences in proportions.

Results: Our observations revealed 20 different emm types and 13 different Haelll vir typing patterns. A $1.2 \mathrm{~kb}$ fragment was found in all Haelll typing pattern. Fragments of $1.2 \mathrm{~kb}$ and $550 \mathrm{bp}$ were conserved in majority of the isolates. Hinfl digestion was found proficient in differentiating the strains of same vir typing patterns. Strong predominance of speC (85\%) and spef (80\%) genes have been observed encoding exotoxins production. 4 isolates were found to be erythromycin resistant and were of genotype emm49. High degree of tetracycline resistance was shown by $53.57 \%$ isolates which belonged to 12 different emm genotypes.

Conclusions: These findings suggested that in addition to emm typing, sequential application of Haell and Hinfl restriction enzymes in vir typing analysis is an effective tool for group A streptococcal molecular characterization associated with antibiotic resistance.
\end{abstract}

Keywords: Streptococcus pyogenes (GAS), emm typing, vir typing, Virulence regulon, Restriction enzyme digestion, Antibiotic sensitivity patterns, Exotoxin gene

\section{Background}

Streptococcus pyogenes or Lancefield group A Streptococcus (GAS) is responsible for a diverse range of clinical manifestations. Acute infection causes pharyngitis, impetigo, scarlet fever, cellulitis, acute bacterial endocarditis and necrotizing fasciitis. Ineffective or delayed treatment, and infection with drug-resistant bacteria eventuates in chronic immune-mediated disorders such as acute rheumatic fever (ARF) and acute glomerulonephritis (AGN) with attended morbidity and mortality worldwide [1-6].

\footnotetext{
* Correspondence: rdipanwita8@gmail.com; bbasudev@rediffmail.com ${ }^{1}$ Biochemistry Research Wing, Department of Biochemistry, Dr. B C Roy Post Graduate Institute of Basic Medical Education and Research (IPGME\&R), 244B, A J C Bose Road, Kolkata 700020, India

Full list of author information is available at the end of the article
}

The fast emergence of antimicrobial resistance amongst S. pyogenes therefore needs molecular characterization of the newly variant strains. The conventional $M$ serotyping is cumbersome, less effective and demand preparatory requirements $[7,8]$. A large number of $S$. pyogenes isolates remains $M$ untypable by the available present range of high titre antisera [9-11]. Alternative techniques used for $\mathrm{emm}$ and vir typing are favored. emm typing is based on sequence analysis of emm gene [8], that encodes for the major virulence factor $M$ and $M$-like proteins while vir typing is based on amplification of virulence regulonspecific polymerase chain reaction (PCR) amplicon followed by restriction fragment length polymorphism (RFLP) [12]. 
Different reports have shown a fair prevalence of GAS infections among children $[6,13,14]$ and strain variations among the GAS isolates $[15,16]$. A sudden worldwide increase in antimicrobial resistance in S. pyogenes has been observed during the last few years [17, 18]. Macrolide resistance among GAS has been widespread $[19,20]$ possibly linking to the spread of a particular clone by selection pressure due to random usage of macrolides [21]. Recent reports on tetracycline resistance identify the ineffectiveness of this drug against infections with GAS [22-26]. Streptococcal pyrogenic exotoxins act as super antigens and stimulate lymphocyte activation to induce fever and extensive proliferation with the consequent massive release of cytokines [27]. Fibronectin binding proteins are considered as major Streptococcal adhesins and amongst them fbp54 is expressed in human host environment [28].

Reports on Streptococcal pyrogenic exotoxin genes and fibronectin binding protein gene expression in noninvasive infections are relatively few from India. The present study tries to establish the correlation of the GAS genotypic variation with the changes in molecular patterns of virulence regulon, antibiotic resistance and expression of pyrogenic exotoxins and fibronectin binding protein genes.

The isolates have been characterized with HaeIII, HinfI and XhoI restriction fragment length polymorphism to evaluate their applicability in vir typing analysis following methodology by Gardiner et al. $[9,12]$.

\section{Methods}

\section{Isolate selection}

The patients presenting with sore throat, different skin lesions and on clinical examination found to be suffering from pharyngitis and/or tonsillitis and pyoderma were selected for study. Samples were collected before administering any antibiotic therapy.

\section{Patient recruitment}

Study patient samples belonged to four age-groups:

Group I 1 month to 3 years [infants]

Group II 4 years to 15 years [school-aged children]

Group III 16 years to 45 years [adults]

Group IV $>45$ years [middle as well as old age groups]

Detailed clinical history, which includes types of throat infections and skin infections, the period of suffering, was recorded. Age, sex, home address and other information of the patients were recorded. $S$. pyogenes was isolated from the samples at the Department of Biochemistry of Dr. B C Roy Post Graduate Institute of Basic Medical Education and Research (IPGME\&R), Kolkata.
Collection of samples from sore throat patients

Samples for throat culture were obtained by swabbing the patient's posterior part of upper respiratory tract with a sterile cotton swab.

\section{Collection of samples from patients with skin infections}

Pus samples were collected using a sterile swab stick from ulcerative lesion of pyoderma infections. In case of unopened abscess pus was collected by aspiration.

We got very insignificant number of $S$. pyogenes isolates (two isolates) from throat samples. Therefore we have summarized and interpreted our observations in respect to non-sever infections which include sore throats and pyoderma/ impetigo. It has been done to avoid any bias that might occur during interpretation of the results.

\section{Sample isolation and storage}

Samples were inoculated in 5\% sheep blood agar and incubated at $37^{\circ} \mathrm{C}$ for $24-48 \mathrm{~h}$. $\beta$ - hemolytic colonies were selected and screened by Gram staining, bacitracin susceptibility test, catalase test, and finally confirmed as Group A Streptococcus by Latex agglutination test using a Streptex kit (Remel, UK). Isolates were stored at $-80{ }^{\circ} \mathrm{C}$ in Brain Heart Infusion Broth containing 30\% glycerol.

\section{emm typing analysis}

emm typing is based on sequence analysis of emm gene encoding for serotype specific M-protein. Genomic DNA was prepared by phenol-chloroform method [29] from bacteria obtained by touching the tips of $\beta$ hemolytic single colonies, obtained by subculture from overnight broth culture (BHI broth, Hi-media, Mumbai, India), to avoid contamination in growth in liquid medium. Bacterial cells were treated with mutanolysin and lysozyme solution for $1 \mathrm{~h}$ at $37^{\circ} \mathrm{C}$. For emm typing analysis, gene was amplified by "all M" primers $[15,30]$, using PTC150 (MiniCycler ${ }^{\mathrm{TM}}$, MJ Research) thermal cycler. PCR amplicon of about $1.4 \mathrm{~kb}$ was then sequenced with the forward primer (5' ATAAGGAGCATAAA AATGGCT $3{ }^{\prime}$ ). Sequencing was done commercially (Chromous Biotech Pvt. Ltd., India). The sequence was subjected to homology search by Blast search analysis (http://www.cdc.gov/ncidod/biotech/strep/ strepblast.htm). Pair-wise comparison of the nucleotide identities of the first 180 to 200 bases of the N-terminal hypervariable region was conducted and strains which showed $\geq 95 \%$ homology with the reference strains were assigned the particular parental emm type [15].

\section{vir typing analysis}

vir typing is based on amplification of virulence regulon that encode for different GroupA Streptococcal virulent proteins. Amplification of vir regulon specific PCR 
amplicon was performed by VUF and SBR primers, as described by Gardiner et al. [12], with few modifications. PCR amplification was carried out in a $50 \mu \mathrm{l}$ reaction mixture containing $5 \mu \mathrm{l}$ of template DNA, $1 \mathrm{U}$ of TaKaRa LA Taq polymerase, LA PCR Buffer II, $2 \mathrm{mM} \mathrm{MgCl}_{2}$, $200 \mu \mathrm{M}$ of each of dATP, dGTP, dCTP and dTTP, $1 \mu \mathrm{l}$ of each $20 \mu \mathrm{M}$ primers. Cycling conditions were modified to include a final extension at $72{ }^{\circ} \mathrm{C}$ for $7 \mathrm{~min}$. Then $5 \mu \mathrm{l}$ of PCR product was electrophoresed on $0.8 \%$ agarose gel to check the quality as well as the quantity of the amplicon. RFLP was carried out in $30 \mu \mathrm{l}$ reaction containing $0.5 \mu \mathrm{g}(10-15 \mu \mathrm{l})$ PCR product, RE buffer, 2U of HaeIII / HinfI / XhoI restriction enzyme from NEB [9, 12]. Digestion was carried out for $1 \mathrm{~h} 30 \mathrm{~min}$. Digests were electrophoresed on $1 \%$ agarose gel and band patterns were analyzed by visual comparison.

\section{Identification of toxin and fibronectin-binding protein genes}

Sequences specific for speA, speB, speC, speF and $f b p-54$ were detected with the primers documented by earlier workers [31]. The primer sequences, annealing temperature and amplicon sizes are given in Table 1. Amplification of all genes was carried out under the following conditions: an initial $5 \mathrm{~min}$ denaturation step at $96{ }^{\circ} \mathrm{C}$, followed by 30 cycles of denaturation at $96{ }^{\circ} \mathrm{C}$ for $55 \mathrm{~s}, 65 \mathrm{~s}$ of annealing at the appropriate temperature for each gene (Table 1), and $70 \mathrm{~s}$ of extension at $72{ }^{\circ} \mathrm{C}$, with a final extension step at $72{ }^{\circ} \mathrm{C}$ for $5 \mathrm{~min}$. All PCR products were electrophoresed on $1.5 \%$ agarose gels. $\phi X 174$ DNA ladder $\left(\mathrm{GeNei}^{\mathrm{TM}}\right)$ and 100 bp Gene ruler (Fermentus) were used as molecular marker.

\section{Determination of antibiotic susceptibility}

The antibiotic sensitivity of all GAS isolates were tested by the modified Kirby-Bauer method, matching inoculum turbidity to McFarland 0.5 [32], on Mueller-Hinton agar with $5 \%$ sheep blood using penicilling (10unit), cefotaxime $(30 \mu \mathrm{g})$, erythromycin $(15 \mu \mathrm{g})$, vancomycin $(30 \mu \mathrm{g})$, tetracycline $(30 \mu \mathrm{g})$ and clindamycin $(2 \mu \mathrm{g})$ [HiMedia, India] disks. Results were interpreted according to Clinical and Laboratory Standards Institute (CLSI) guidelines provided by the CLSI, 2012, as per manufacturer's instructions [33]. Streptococcus pyogenes ATCC19615 strain was used as control.

\section{Statistical analysis}

Majority of counts have been summarized by percentages, key proportion has been expressed within 95\% confidence interval. Statistical analysis was done using one-way ANOVA. P value with $P<0.05$ was considered significant, a difference with $P<0.0001$ was considered highly significant.

\section{Results}

Isolation of Streptococcus pyogenes and emm genotype diversity

Samples were collected from tertiary referral health care hospitals in Kolkata. As these are the most important referral Government hospitals, a large number of patients from different community attend these hospitals. Prior informed consent and clearance from institutional ethical committee were obtained. Samples were collected from patients attending skin and E.N.T OPD of Seth Sukhlal Karnani Memorial Hospital (SSKM) hospital and Calcutta National Medical College \& Hospital, from 2009 to December, 2011.

Detailed analysis of isolates from 270 cases identified $140(51.8 \%)$ as GAS expressing interpretable emm types. These isolates represented 20 different emm types, indicating $14.28 \%$ heterogeneity. The sizes of the amplicon were around $1.4 \mathrm{~kb}$. The most common emm types among the obtained emm types was emm49 (Additional file 1) (17.85\%), followed by emm 25 (Additional file 2) (12.14\%), emm77 (10.71\%). The observed frequency for each of emm9, emm80, emm92 and emm81 was $6.42 \%$. Others were found in very low percentages (Fig. 1a).

Regarding correlations of emm typing with age groups, our observations revealed that infants ( 1 month- 3 years) were frequently infected by $e m m 49$ (75\%; $P$ value $<0.0001$ ), whereas $18.7 \%$ school aged children (group II) were affected by emm25 $(P$ value $=0.0004)$, followed by

Table 1 Sequences of the PCR primers

\begin{tabular}{|c|c|c|c|c|}
\hline Target gene & Primer sequence $\left(5^{\prime}-3^{\prime}\right)$ & Annealing temp $\left({ }^{\circ} \mathrm{C}\right)$ & Amplicon size (bp) & Reference \\
\hline speA & $\begin{array}{l}\text { FW-5'-TAA GAA CCA AGA GAT GG-3' } \\
\text { RV-5'-ATT CTT GAG CAG TTA CC-3' }\end{array}$ & 44 & 248 & Vlaminckx et al., [31] \\
\hline speB & $\begin{array}{l}\text { FW-5'-AAG AAG CAA AAG ATA GC-3' } \\
\text { RV-5'-TGG TAG AAG TTA CGT CC-3' }\end{array}$ & 42 & 955 & \\
\hline spec & $\begin{array}{l}\text { FW-5'- GAT TTC TAC TTA TाT CAC C-3' } \\
\text { RV-5'-AAA TAT CTG ATC TAG TCC C-3' }\end{array}$ & 42 & 584 & \\
\hline speF & $\begin{array}{l}\text { FW-5'- TAC TTG GAT CAA GAC G-3' } \\
\text { RV-5'-GTA ATT AAT GGT GTA GCC-3' }\end{array}$ & 42 & 782 & \\
\hline$f b p-54$ & $\begin{array}{l}\text { FW-5'-CTT CAG AAT CTG TाT CTT TG-3' } \\
\text { RV-5'-AGT TCA CAG GTT GTC TAT TG-3' }\end{array}$ & 48 & 595 & \\
\hline
\end{tabular}




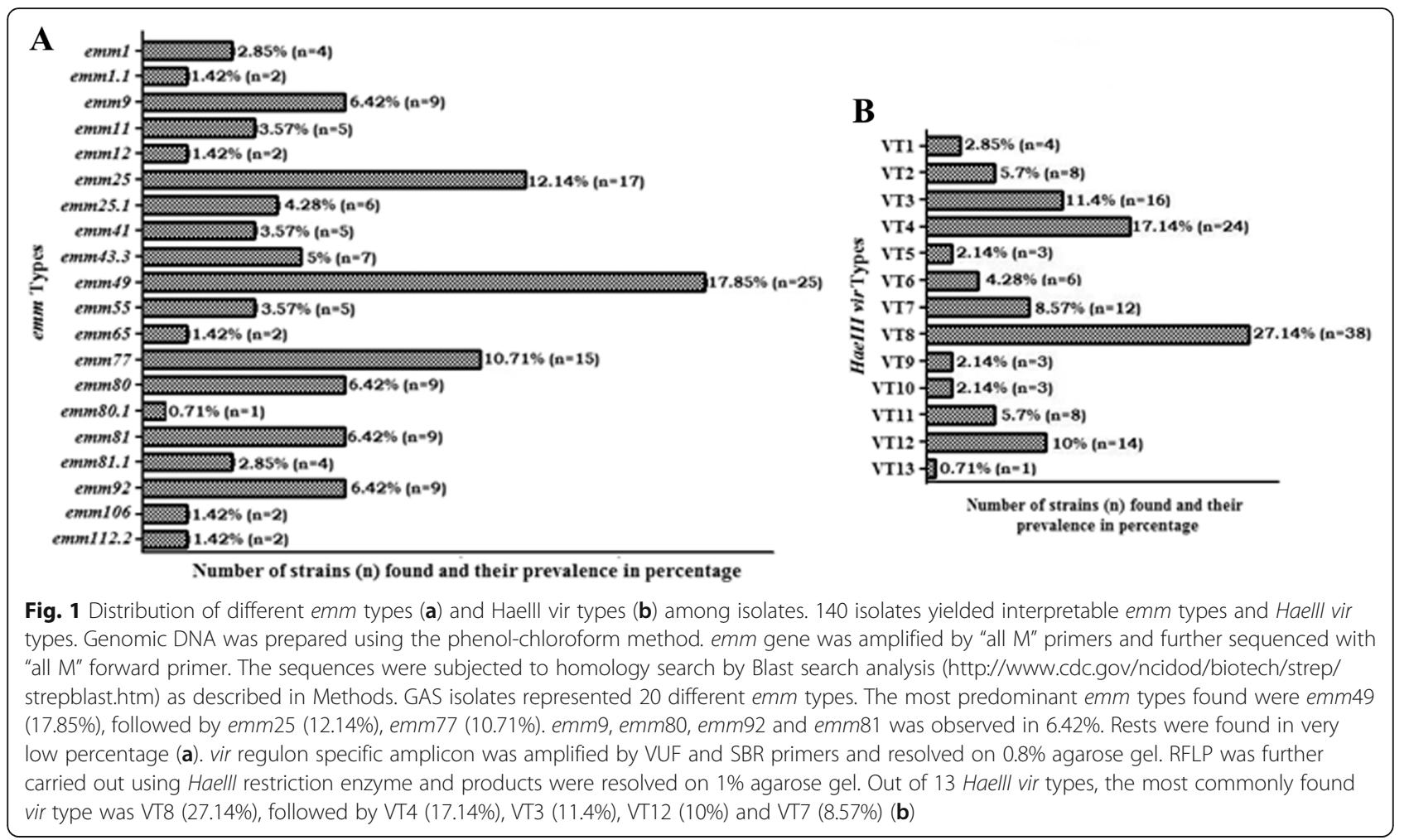

emm92 genotype (14.5\%; $P$ value $=0.001)$. A few emm strains were found in adults belonging to group III (15.6\% of emm77; $P$ value $=0.008$ ), and middle or old aged patients in group IV (16.6\% of emm 9 , emm 25 and emm11 each; $P$ value $=0.0004)$ (Fig. 2 ).

\section{vir typing patterns diversity}

In the present study, 13 different vir types among 140 isolates (9.2\%) were observed. vir types had been identified by RFLP with HaeIII restriction enzyme. All isolates were typeable with HaeIII enzyme, showing 3-7 bands ranging from $200 \mathrm{bp}$ to $4 \mathrm{~kb}$. The isolates showed a common band at $1.2 \mathrm{~kb}$, and majority of isolates shared fragments at around $200 \mathrm{bp}$ and $550 \mathrm{bp}$ (Fig. 3). Out of 13 different $v$ ir types, the most commonly found vir type was VT8 (27.14\%), followed by VT4 (17.14\%), VT3 (11.4\%), VT12 (10\%) and VT7 (8.57\%). In our study VT1 represented the reference strain type of ATCC 19615 (Fig. 1b).

On comparing emm genotype with HaeIII vir typing patterns, it was found that emm49, emm25, emm80, emm12 matched with co-existence of VT8, VT3, VT1 and VT4 respectively. In contrast, VT8 was also associated with emm65, emm11, emm77, and VT12 with emm92 and emm9. VT3 pattern was observed both in emm25 type and emm25.1 subtype. On the other hand, emm81/ emm81.1 were noted with VT11 and VT9 respectively, and emm1/ emm1.1 with VT6, VT10 respectively (Table 2).
The second restriction enzyme HinfI, documented 21 different vir typing patterns $\left(\mathrm{VT}_{1}-\mathrm{VT}_{21}\right)$. HinfI digestion was found to generate 6-10 bands, which were around $250 \mathrm{bp}$ to $2 \mathrm{~kb}$ (Fig. $4 \mathrm{a}$ \& b). HinfI was found to generate same or different typing patterns for the isolates those producing identical HaeIII typing patterns. In comparing the typing patterns of HaeIII and HinfI digestions, HinfI enzyme was found to discriminate VT8 HaellI digestion type into five more subtypes $\left(\mathrm{VT}_{3}, \mathrm{VT}_{4}, \mathrm{VT}_{8}, \mathrm{VT}_{12}\right.$, and $\left.\mathrm{VT}_{16}\right)$, VT4 HaeIII type into another four more subtypes $\left(\mathrm{VT}_{2}, \mathrm{VT}_{6}, \mathrm{VT}_{7}, \mathrm{VT}_{18}\right)$ and each of VT1, VT2, VT3 into two more subtypes (Table 2).

In our study, the third restriction analysis by digestion with XhoI recognized 6 different typing patterns (VTi-VTvi), with fragments around 1 to $6 \mathrm{~kb}$ among 140 isolates (Fig. 5). Study showed the most frequent VT patterns by XhoI digestion were 34.28, 14.99, and $12.85 \%$ for VTv, VTiii and VTiv respectively. VTvi, showing only a minor band, was found in $24.99 \%$ isolates.

\section{Identification of exotoxin and fibronectin-binding protein genes}

Study highlighted that only $6(4.2 \%)$ isolates was found to contain speA gene, whereas majority of isolates contained speC (85\%) and speF (80\%) genes. The rate of occurrence of $s p e B$ and $f b p-54$ genes was 58 and $30 \%$, respectively. 


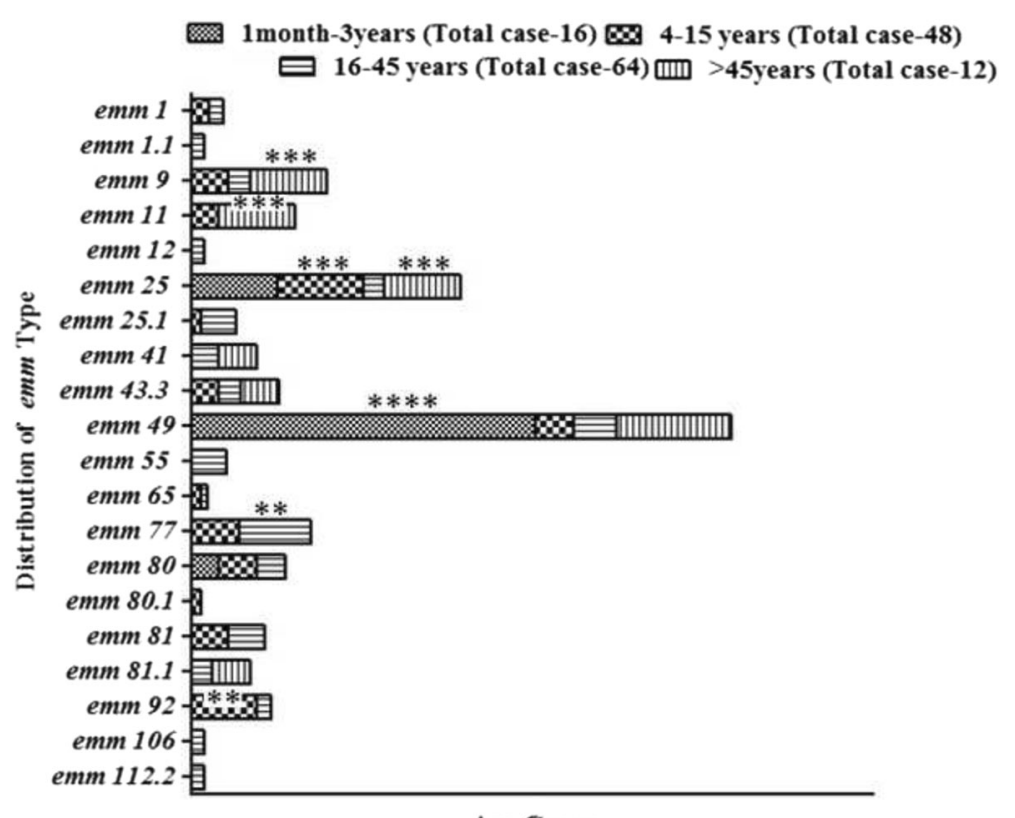

Age Group

Fig. 2 Distribution of different emm types among age groups. Patient samples were categorized in four age-groups as mentioned in Methods. Genomic DNA was prepared using the phenol-chloroform method. emm gene was then amplified by "all M" primers and further sequenced with "all M" forward primer. The sequence obtained was then subjected to homology search by Blast search analysis (http:// www.cdc.gov/ncidod/biotech/strep/ strepblast.htm). Distribution of different emm types among age groups was expressed in percentages as described in Methods. emm types of group A streptococci isolated from different age groups revealed that infants (1 month-3 years) are frequently infected by emm49 (75\%), school-going children (group II) are primarily affected by emm25 (18.7\%) and emm92 (14.5\%). A few emm strains were detected in adults (group III, 15.6\% of emm77) and middle or old aged patients (group IV 16.6\% of emm9, emm25 and emm 11 each). Asterisks indicate a statistically significant correlations ( ${ }^{* * * *} P<0.0001,{ }^{* * *} P=0.0004$ and $\left.{ }^{* *} P=0.001,0.008\right)$

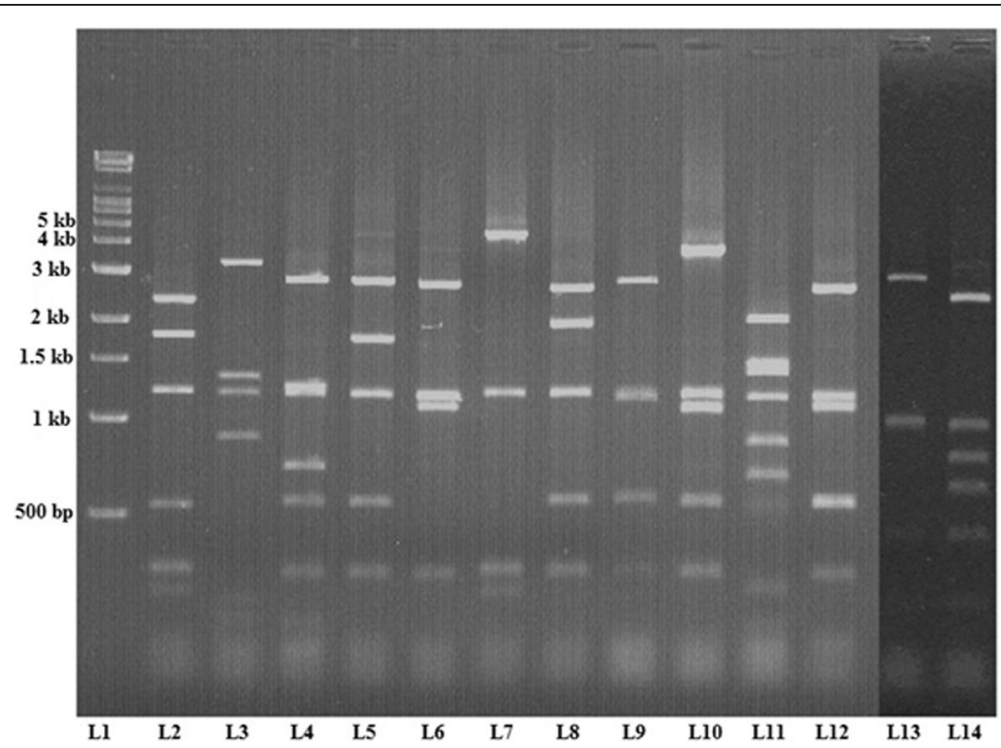

Fig. 3 1\% Agarose gel containing RFLP profile (vir type) of Haelll digested PCR products. Genomic DNA was prepared using the phenol-chloroform method. vir regulon specific amplicon was amplified by VUF and SBR primers and resolved on $0.8 \%$ agarose gel. RFLP was further carried out as described in Methods using Haell restriction enzyme and products were resolved on $1 \%$ agarose gel. Lane $1=10 \mathrm{~kb}$ Super mix marker; Lanes 2-14=VT1- VT13 
Table 2 Comparison of emm typing/Haelll vir typing/ Hinfl vir typing of GAS isolates

\begin{tabular}{lll}
\hline emm type & Corresponding Haell vir types & Corresponding Hinfl vir types \\
\hline emm1 & $\mathrm{VT6}$ & $\mathrm{VT}_{1}$ \\
emm1.1 & $\mathrm{VT10}$ & $\mathrm{VT}_{14}$ \\
emm9 & $\mathrm{VT12}$ & $\mathrm{VT}_{4}$ \\
emm11 & $\mathrm{VT} 8$ & $\mathrm{VT}_{8}$ \\
emm12 & $\mathrm{VT} 4$ & $\mathrm{VT}_{2}, \mathrm{VT}_{6}, \mathrm{VT}_{7}, \mathrm{VT}_{18}$ \\
emm25 & $\mathrm{VT} 3$ & $\mathrm{VT}_{5}$ \\
emm25.1 & $\mathrm{VT3}$ & $\mathrm{VT}_{11}$ \\
emm41 & $\mathrm{VT} 6$ & $\mathrm{VT}_{17}$ \\
emm43.3 & $\mathrm{VT7}$ & $\mathrm{VT}_{18}$ \\
emm49 & $\mathrm{VT} 8$ & $\mathrm{VT}_{3}, \mathrm{VT}_{4}$ \\
emm55 & $\mathrm{VT2}$ & $\mathrm{VT}_{9}, \mathrm{VT}_{20}$ \\
emm65 & $\mathrm{VT} 8$ & $\mathrm{VT}_{16}$ \\
emm77 & $\mathrm{VT8}$ & $\mathrm{VT}_{3}, \mathrm{VT}_{12}$ \\
emm80 & $\mathrm{VT1}$ & $\mathrm{VT}_{15}, \mathrm{VT}_{19}$ \\
emm80.1 & $\mathrm{VT5}$ & $\mathrm{VT}_{10}$ \\
emm81 & $\mathrm{VT11}$ & $\mathrm{VT}_{21}$ \\
emm81.1 & $\mathrm{VT9}$ & $\mathrm{VT}_{13}$ \\
emm92 & $\mathrm{VT12}$ & $\mathrm{VT}_{4}$ \\
emm106 & $\mathrm{VT} 8$ & $\mathrm{VT}_{4}$ \\
emm112.2 & $\mathrm{VT} 13$ & $\mathrm{VT}_{4}$ \\
\hline
\end{tabular}

\section{Evaluation of antibiotic susceptibility patterns of}

\section{S. pyogenes}

In the present study, isolates were found highly sensitive (76.42\%) to penicillin with $23.57 \%$ of intermediate susceptibility. Erythromycin sensitivity was very high (88.57\%), and only 4 (2.85\%) found resistant (95\% CI$0.09 \%-05.61)$. All isolates were susceptible to vancomycin and clindamycin. Cefotaxime sensitivity was very high (91.42\%) with only $8.57 \%$ of isolates showing intermediate sensitivity. By contrast, resistance $(53.57 \%)$ and intermediate resistance $(21.42 \%)$ to tetracycline were high (Table 3).

\section{Correlation of antibiotic susceptibility patterns with emm typing}

Relation between emm types and antibiotic sensitivity patterns was evaluated for studying their correlations. Strain $\mathrm{emm} 43.3$ and $e m m 9$ were found to be sensitive to all six antibiotics. Three children and one adult showing erythromycin resistance cases were of genotype emm49. Out of $20 \mathrm{emm}$ types documented, $12 \mathrm{emm}$ types were found responsible for tetracycline-resistance (Table 4).

\section{Discussion}

In the present study, the emm and vir type diversity among GAS isolates obtained from different patients was analyzed. Reports by earlier workers documented 57.5, 19.71 and 40\% heterogeneity with emm49, emm77 and $e m m 74$ genotypes to be the most prevalent types respectively [15, 34, 35]. In another study, 32.35\% heterogeneity was reported [16]. A Norweigian study revealed $44 \%$ variation with $e m m 1$ to be the most prevalent genotype [36]. In a recent outbreak of GAS infections, the most uncommonly reported emm type 58 was shown to be most frequent isolate [37].

In present study, emm typing resulted in $14.28 \%$ heterogeneity in the isolated GAS strains which is indicative of lower strain variation in this context. The most detectable type found was emm 49 (17.85\%). Thus different values of heterogeneity in the isolates were observed by the present and earlier investigators, might be due to variation of prevalent strains in different geographical regions having different climatic conditions. It could possibly be predicted that the genetic heterogeneity
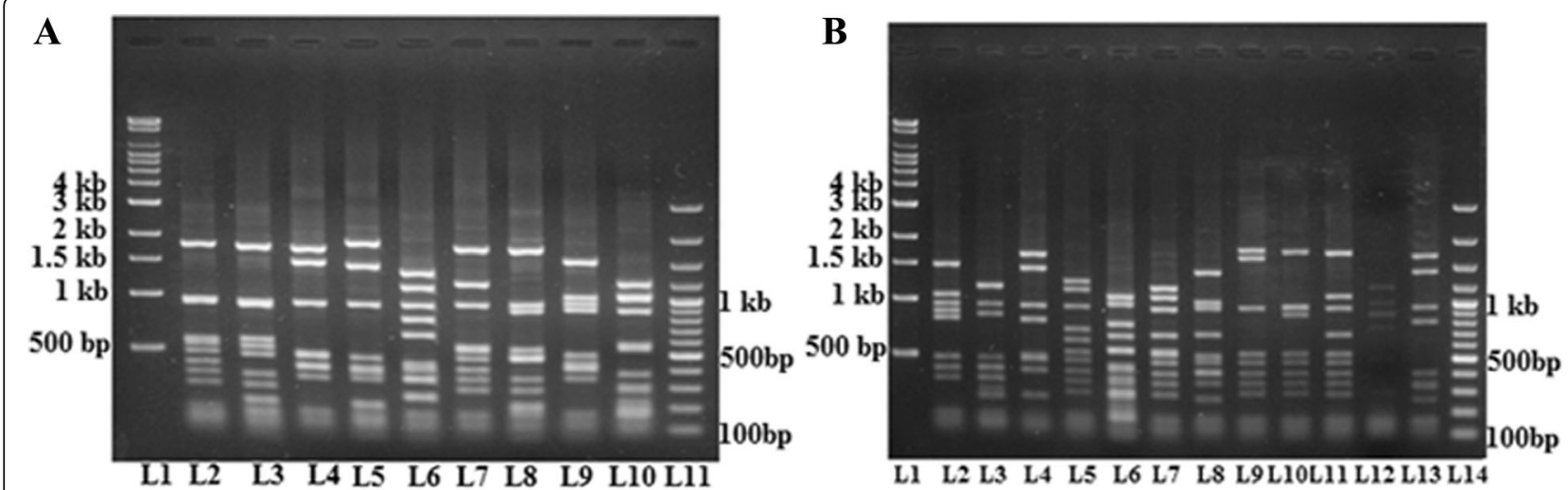

Fig. 4 1\% Agarose gel containing RFLP profile (vir type) of Hinfl digested PCR products. Genomic DNA was prepared using the phenol-chloroform method. vir regulon specific amplicon was amplified by VUF and SBR primers and resolved on 0.8\% agarose gel. RFLP was performed using Hinfl restriction enzyme and the products were resolved on 1\% agarose gel. Lane $1=10 \mathrm{~kb}$ Super mix marker; Lanes 2-10 = VT 1 - VT ; Lane11 = 100 bp marker (a). Lane $1=10 \mathrm{~kb}$ Super mix marker; Lanes 2-13=VT $10-\mathrm{VT}_{21}$; Lane $14=100 \mathrm{bp}$ marker (b) 


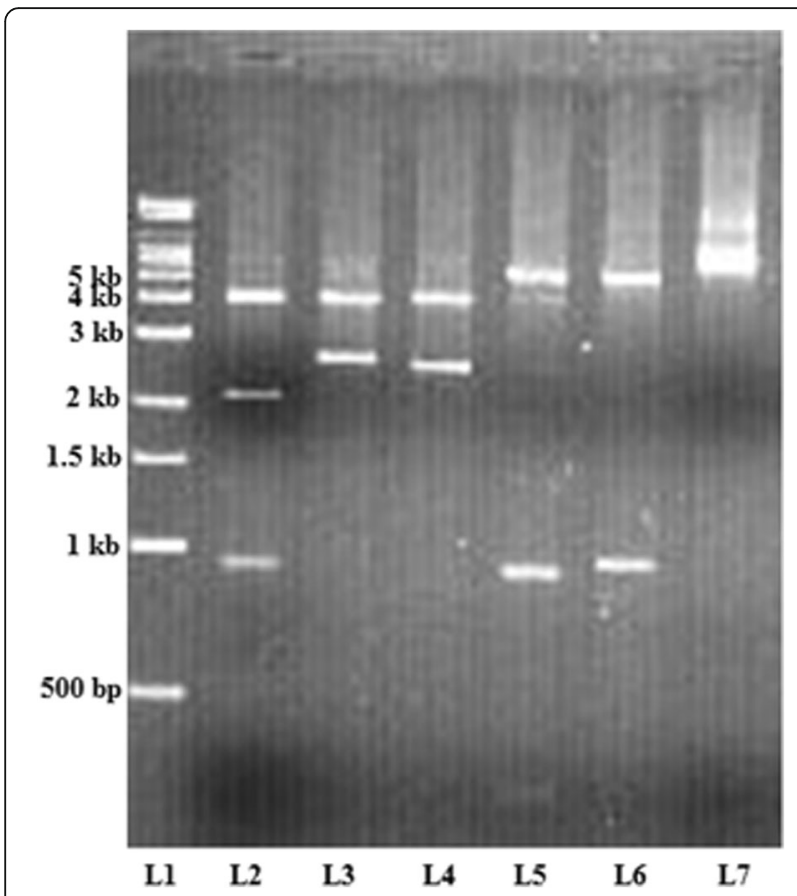

Fig. 5 1\% Agarose gel containing RFLP profile (vir type) of Xhol digested PCR products. Genomic DNA was prepared using the phenol-chloroform method. vir regulon specific amplicon was amplified by VUF and SBR primers and resolved on $0.8 \%$ agarose gel. RFLP was performed using Xho/ restriction enzyme and the products were resolved on $1 \%$ agarose gel. Lane $1=10 \mathrm{~kb}$ Super mix marker; Lanes 2-7 = VTi- VTVi

could be temperature and humidity dependent, however this fact requires a complete different investigation. The results of this study demonstrated some emm types and their subtypes, like emm81/emm81.1, emm25/emm25.1 and emm1/emm1.1, emerged due to point mutation, reflecting in the origin of $\mathrm{N}$-terminal $\mathrm{emm}$ sequence variability and implying the importance of emm strain typing (sequencing data not shown).

As children are more susceptible to GAS infections [38-40], and as associated emm-types and clinical presentations are influenced by population immunity and strain tropism [41], the emm distribution patterns in relation to patient's age, the children in particular, are significant. In this study occurrence of S. pyogenes infection was found average. As children are more susceptible to GAS infections with attendant life-threatening remote sequelas (RHD and AGN) as well, it is believed that the dominance of emm 49 as well as other frequently occurring emm types in infant and children needs an independent and systematic study on association of immunological parameters with emm types.

Vir typing measures the changes in the region of the genome that determines major virulence factors that are involved in anti-phagocytic activity, attachment, colonization and in avoiding recognition by the immune systems [12]. The HaeIII vir typing patterns in the present study were found dissimilar to other reported typing patterns. So we assigned our own VTs to analyze the typing patterns of the isolates from eastern region of India. We screened 13 vir types from 140 isolates by HaeIII digestion, which accounted 9.28\% diversity in GAS isolates. Here we observed that vir types were entirely different from the reported typing patterns of Australia, Romania and northern India. HaeIII vir typing patterns of Australian GAS isolates produced 4 to 8 fragments ranging from $200 \mathrm{bp}$ to $4 \mathrm{~kb}$, where $1.4 \mathrm{~kb}$, $500 \mathrm{bp}$, and $275 \mathrm{bp}$ were found common in the isolates tested [9]. vir typing patterns of Romania yielded 2 to 8 fragments ranging from $100 \mathrm{bp}$ to $4.2 \mathrm{~kb}$ with a common fragment at $1.2 \mathrm{~kb}$ [42]. Reports from north India showed 4 to 6 fragments varying from $300 \mathrm{bp}$ to $5 \mathrm{~kb}$ where $300 \mathrm{bp}, 550 \mathrm{bp}$ and $1.2 \mathrm{~kb}$ were common for the majority of isolates [15]. We found 3 to 7 fragments of $200 \mathrm{bp}$ to $4 \mathrm{~kb}$ and a $1.2 \mathrm{~kb}$ fragment was found common to all isolates. The majority of isolates shared the fragments of around $200 \mathrm{bp}(81.42 \%)$ and $550 \mathrm{bp}$ (87.85\%). On comparing our present findings with those previous observations, a $1.2 \mathrm{~kb}$ fragment was found common in most of the study regions (except Australian typing patterns). In India, in addition to $1.2 \mathrm{~kb}$, a $550 \mathrm{bp}$ was also found common to the majority of isolates. Thus, these two segments of the virulence regulon of S. pyogenes remain conserved in Indian strain types.

The overlaps between emm and vir typing showed that one specific emm type was always represented by one

Table 3 Antibiotic susceptibility patterns of S. pyogenes

\begin{tabular}{|c|c|c|c|c|}
\hline \multirow{2}{*}{$\begin{array}{l}\mathrm{Sl} \\
\text { No. }\end{array}$} & \multirow{2}{*}{$\begin{array}{l}\text { Antimicrobial agent } \\
\text { (amount/disk) }\end{array}$} & \multicolumn{3}{|c|}{ Patterns of susceptibility (in percentage) with respect to diameter of zone of inhibition in $\mathrm{mm}$} \\
\hline & & Resistant & Intermediate & Sensitive \\
\hline 1. & PenicillinG (10unit) & - & $33(23.57 \%)$ & $107(76.42 \%)$ \\
\hline 2. & Erythromycin (15mcg) & $4(2.85 \%)$ & $12(8.57 \%)$ & $124(88.57 \%)$ \\
\hline 3. & Cefotaxime (30mcg) & - & $12(8.57 \%)$ & $128(91.42 \%)$ \\
\hline 4. & Vancomycin (30mcg) & - & - & $140(100 \%)$ \\
\hline 5. & Tetracycline (30mcg) & 75 (53.57\%) & $30(21.42 \%)$ & 35 (24.99\%) \\
\hline 6. & Clindamycin (2mcg) & - & - & 140 (100\%) \\
\hline
\end{tabular}


Table 4 Association between emm types and antibiotic sensitivity patterns

\begin{tabular}{|c|c|c|c|c|}
\hline \multirow{2}{*}{$\begin{array}{l}\text { SI } \\
\text { No. }\end{array}$} & \multirow{2}{*}{$\begin{array}{l}\text { Antimicrobial } \\
\text { agent }\end{array}$} & \multicolumn{3}{|l|}{ Susceptibility of emm types } \\
\hline & & Sensitive & Intermediate & Resistant \\
\hline 1. & PenicillinG & $\begin{array}{l}\text { emm-25, 25.1, 49, 80, 9, 11, 81, 81.1, 43.3, 106, 41, 92, 77, 55, } \\
1\end{array}$ & $\begin{array}{l}\mathrm{emm}-112.2,25,49,81,1.1 \\
65,80.1,12\end{array}$ & - \\
\hline 2. & Cefotaxime & $\begin{array}{l}\text { emm- } 25,25.1,49,80,80.1,9,11,81,81.1,106,41,43.3,92 \\
77,55,1,1.1\end{array}$ & $\begin{array}{l}\text { emm- } 25,49,81,12,112.2 \\
65\end{array}$ & - \\
\hline 3. & Erythromycin & $\begin{array}{l}\text { emm-43.3, 25, 25.1, 49, 80, 80.1, 9, 11, 12, 81, 81.1, 106, 41, } \\
92,77,55,1,1.1\end{array}$ & emm-49, 112.2, 65, 1 & emm-49 \\
\hline 4. & Clindamycin & $\begin{array}{l}\text { emm- } 25,25.1,49,43.3,80,80.1,1,1.1,9,11,12,81,81.1,106 \\
41,92,77,55,112.2,65\end{array}$ & - & - \\
\hline 5. & Tetracycline & emm- $25,43.3,49,9,77,80.1,81,65$ & $\begin{array}{l}\text { emm-25.1, 80, 49, 81, 81.1, } \\
12\end{array}$ & $\begin{array}{l}\text { emm-1, 1.1, 41, 55, 81, 81.1, 77, 49, } \\
11,106,112.2,92\end{array}$ \\
\hline 6. & Vancomycin & $\begin{array}{l}\text { emm- } 25,25.1,49,43.3,80,80.1,1,1.1,9,11,12,81,81.1,106 \\
41,92,77,55,112.2,65\end{array}$ & - & - \\
\hline
\end{tabular}

particular vir type whereas one vir type was shared by more than one emm types. However, in two cases, different VTs were obtained for isolates of one emm type and its subtype. This finding supports the concept that the heterogeneity demonstrated by vir typing is primarily due to variations among emm genes rather than diversity in the architecture of the vir regulon [9] and thus, an insertion or deletion of one or more nucleotide not only categorizes a specific emm type into its subtypes but also changes the expression of its virulence regulon. Thus vir typing analysis is found more informative than emm typing, regarding architectural variation of virulence regulon conferring the virulence on $S$. pyogenes.

Furthermore the use of the second restriction enzyme HinfI appeared to be very useful in discriminating HaeIII typed isolates, which supports the concept of Gardiner et al. [9]. In the present study, though HinfI was found proficient in distinguishing the isolates of the same HaeIII vir types and also generate more fragments comparing HaeIII but it did not generate any conserved fragments, unlike HaeIII digestion. Therefore, successive use of these two enzymes can be a tool for vir typing analysis. XhoI digestion produced fewer fragments and was less informative.

In order to study the strain characteristics contributing to virulence patterns, the isolates were evaluated for the presence of different toxin and fibronectin binding protein genes. Extracellular proteins that reportedly play a role in the pathogenesis of GAS are represented by streptococcal exotoxins, a few of which have superantigenic properties that allow them to activate large subsets of $\mathrm{T}$ cells, with massive cytokine release as a consequence [31]. Previous report from India showed lower incidence of speA gene (5.8\%) and higher incidence of speB and speF gene $(92.3,86.5 \%)$ in noninvasive infection [43]. In contrast, the current study showed speA gene less contributing for GAS infections, whereas the observed predominant occurrence of speC and speF genes strongly suggest their association with incidence of infections. Association of $\mathrm{SpeB}$ and $f b p-54$ genes was noticed in less number of cases and probably partly contributes towards virulence. It is of considerable interest to study the correlation of these exotoxin gene expressions with cytokines activation in this region by further study.

Another important aspect of this study is GAS antibiotic sensitivity patterns and their correlation with $\mathrm{emm}$ genotyping. Penicillin has been used routinely for treating GAS infections for over 50 years, and yet GAS has remained penicillin susceptible $[44,45]$. Since penicillin may be given at higher doses without ill effects, the observed intermediate sensitivity in our study may have less impact. A study from north India [7] showed diminished susceptibility in $20.6 \%$ of strains which is in support of our observation but contrast to previous reports of $100 \%$ susceptibility [46, 47]. Erythromycin resistance and therapeutic failure have been observed to be on the rise worldwide due to their increased medicament [48-50]. In this study, sensitivity to erythromycin was found very high. The observed erythromycin resistant cases were though small in number, but alarming in this region as these were obtained mostly from children, and erythromycin is the $1^{\text {st }}$ alternative drug of choice for penicillin hypersensitive patients as well. Interestingly, all four erythromycin resistant strains were of genotype emm49, suggesting that the genotype's association with the emerging erythromycin-resistance in this region. Association of erythromycin resistance and emm typing has been documented earlier. emm12 from Korea and Japan [51], emm12 and emm75 from Pittsburgh [52], emm90 from Hawaii [53], emm 4, emm 28, and emm 77 from Western Greece [54] showed strong association with erythromycin resistance. In present study, association is different from earlier workers as emm49 was constantly associated with the erythromycin resistance. In spite of clindamycin resistance report [55] earlier, all isolates of present study were 
found sensitive to clindamycin and vancomycin. High tetracycline resistance among $S$. pyogenes isolates have been reported from different parts of the World [22, 44, $56,57]$. In the present study, high percentage of resistance was shown by tetracycline, which is in corroboration with the previous findings. 14 and 28 different tetracyclineresistant $\mathrm{emm}$ types were identified in studies from Spain and Tunisia, respectively $[58,59]$. Present study identified 75 tetracycline-resistant isolates, belonging to 12 different emm genotypes. These findings indicated that for study of different regions, $S$. pyogenes strains are approaching tetracycline-resistance, attributable to modifications in tet (M) gene commonly associated with the conjugative transposon Tn916 [59].

\section{Conclusion}

The findings in this study highlight a novel vir-emm correlative dual genotyping analysis with implications in the development of a universally effective vaccine and a new diagnostic tool. speC and speB exotoxins may have important contribution to noninvasive Streptococcal infections. Observations on antibiotic sensitivity patterns emphasized the need for continued monitoring of antibiotic sensitivity and genotyping of $S$ pyogenes for reducing the burden of antibiotic resistance.

\section{Additional files}

Additional file 1: sequencing data emm25. (TIF $741 \mathrm{~kb}$ )

Additional file 2: sequencing data emm49. (TIF $690 \mathrm{~kb}$ )

\section{Abbreviations}

AGN: Acute glomerulonephritis; ARF: Acute rheumatic fever; BHI broth: Brain heart infusion broth; CLSI: Clinical and Laboratory Standards Institute; E.N.T. OPD: Ear nose and throat outpatient department; GAS: GroupA Streptococcus; PCR: Polymerase chain reaction; RFLP: Restriction fragment length polymorphism; RHD: Rheumatic heart disease; S. pyogenes: Streptococcus pyogenes

\section{Acknowledgments}

We would like to thank all of the patients who participated in this study. The Director of IPGME\&R is gratefully acknowledged for providing space and other infrastructural facilities. We are also thankful to Dr. Bhaskar Saha (National Centre for Cell Sciences, Pune, India), Mr. Sanjoy Ghosh and Miss. Shatabdi Ghosh for critical review of the manuscript.

\section{Funding}

This work was supported by Indian Council of Medical Research, Government of India (Sanction No. 5/4/1-3/07-NCD-II Dated 30.03.09).

\section{Availability of data and materials}

All data sets supporting our findings are found in main manuscript and also available from the corresponding author on reasonable request. The sequencing data of emm genotyping study are available in supporting documents. Patients' data will remain de-identified to keep their privacy.

\section{Authors' contributions}

Conceived and designed the experiments: BB and DR. Performed the experiments: DR. Contributed reagents/materials/analysis tools: BB, NKP, SSaha and SSinha. Analyzed the data: DR. Wrote the paper: DR and BB. All authors read and approved the final manuscript.

\section{Competing interests}

In the past five years neither any organizations lose financially from that publication of this manuscript nor have any other financial competing interests. The authors declare that they have no competing interests.

\section{Consent for publication}

Not applicable.

\section{Ethics approval and consent to participate}

The present study content and procedures were approved by the Institutional Ethics Committee of the Institute of Post-Graduate Medical Education and Research (IPGME\&R), Kolkata, India (Ref. no.-Inst/IEC/1833). Written informed consent forms were collected from each patient before the interview and sample collection for the study. In case of children, written consents were collected from their legal guardian. Patients were free to refuse participation without affecting their treatments.

\section{Author details}

${ }^{1}$ Biochemistry Research Wing, Department of Biochemistry, Dr. B C Roy Post Graduate Institute of Basic Medical Education and Research (IPGME\&R), 244B, A J C Bose Road, Kolkata 700020, India. ${ }^{2}$ Health and Family Welfare Department, Directorate of Medical Education, Government of Tripura, 799001, Agartala, Tripura, India. ${ }^{3}$ Nil Ratan Sarkar Medical College and Hospital, Kolkata, India. ${ }^{4}$ The West Bengal University of Health Sciences, Kolkata, India.

Received: 23 July 2016 Accepted: 29 November 2016

Published online: 12 December 2016

\section{References}

1. Katz AR, Morens DM. Severe Streptococcal infections in historical perspective. Clin Infect Dis. 1992;14:298-307.

2. Andersen MM, Ronne T. Group A Streptococcal bacteraemias in Denmark 1987-89. J Infect. 1995;31(1):33-7.

3. O'Loughlin RE, Roberson A, Cieslak RP, Lynfield R, Gershman K, et al. Active Bacterial Core Surveillance Team. The Epidemiology of Invasive Group A Streptococcal Infection and Potential Vaccine Implications: United States, 2000-2004. Clin Infect Dis. 2007;45:853-62.

4. Lamagni TL, Efstratiou A, Dennis J, Nair P, Kearney J, George R, on behalf of the national incident management team. Increase in invasive GroupA Streptococcal infections in England, Wales and Northern Ireland, 2008-2009. Eurosurveillance. 2009;14:1-2

5. Sharma M, Saxena A, Kothari SS, et al. Acute rheumatic fever in children: experience from a cardiac centre. Indian Heart J. 1999;51:652

6. Nandi S, Kumar R, Ray P, Vohra H, Ganguly NK. Group A Streptococcal sore throat in a periurban population of northern India: a one-year prospective study. Bull WHO. 2001;79:528-33.

7. Lancefield RC. Current knowledge of the type specific M antigens of Group A Streptococci. J Immunol. 1962;89:307-13.

8. Beall B, Facklam R, Thompson T. Sequencing emm specific PCR products for routine and accurate typing of group A Streptococcus. J Clin Microbiol. 1996;34:953-8.

9. Gardiner DL, Goodfellow AM, Martin DR, Sriprakash KS. Group A Streptococcal Vir Types are M-Protein Gene (emm) Sequence Type Specific. J Clin Microbiol. 1998;36:902-7.

10. Kaplan EL, Johnson DR, Nanthapisud P, Sirilertpanrana S, Chumdermpadetsuk S. A comparison of Group A Streptococcal serotypes isolated from the upper respiratory tract in the USA and Thailand: implications. Bull WHO. 1992;70:433-7.

11. Relf WA, Martin DR, Sriprakash KS. Identification of sequence types among the M-nontypeable Group A Streptococci. J Clin Microbiol. 1992;30:3190-4.

12. Gardiner DL, Hartas J, Currie B, Mathews JD, Kemp DJ, et al. Vir-typing: a long PCR typing method for Group A Streptococci. PCR Methods Appl. 1995;4:288-93.

13. Capoor MR, Nair D, Dev M, Batra K, Aggarwal P. Resistance to Erythromycin and Rising Penicillin MIC in Streptococcus Pyogenes in India. Jpn J Infect Dis. 2006;59:334-6.

14. Lloyd C, Balakrishnan N, Menon T. vir types of Streptococcus pyogenes in Chennai, South India. J M M Correspondence. 2008;57(9):1176-7. 
15. Sagar V, Bakshi DK, Nandi S, Ganguly NK, Kumar R, et al. Molecular heterogeneity among north Indian isolates of Group A Streptococcus. Lett Appl Microbiol. 2004;39:84-8.

16. Menon T, Whatmore AM, Srivani S, Kumar MP, Anbumani N, et al. emm types of Streptococcus pyogenes in Chennai. Indian. J Med Microbiol. 2001;19:161-2.

17. Szczypa K, Sadowy E, Izdebski R, Hryniewicz W. A rapid increase in macrolide resistance in Streptococcus pyogenes isolated in Poland during 1996-2002. J Antimicrob Chemother. 2004;54:828-31.

18. Arvand M, Hoeck M, Hahn H, Wagner J. Antimicrobial resistance in Streptococcus pyogenes isolates in Berlin. J Antimicrob Chemother. 2000;46:621-3.

19. Bozdogan B, Appelbaum PC, Kelly LM, Hoellman DB, Andrasevic AT, et al. Activity of telithromycin compared with seven other agents against 1039 Streptococcus pyogenes pediatric isolates from ten centers in central and eastern Europe. Clin Microbiol Infect. 2003;9:741-5.

20. Schlegel L, Merad B, Rostane $H$, Broc V, Bouvet A. In vitro activity of midecamycin diacetate, a 16-membered macrolide, against Streptococcus pyogenes isolated in France, 1995-1999. Clin Microbiol Infect. 2001;7:362-6.

21. Betriu C, Culebras E, Redondo M, Avial IR, Gomez M, et al. Prevalence of macrolide and tetracycline resistance mechanisms in Streptococcus pyogenes isolates and in vitro susceptibility to telithromycin. J Ant Chemother. 2002;50:433-42

22. Gattringera R, Sauermann R, Laglera H, Sticha K, Buxbaumc A, et al. Antimicrobial susceptibility and macrolide resistance genes in Streptococcus pyogenes collected in Austria and Hungary. J Antimicrob Agents. 2004;24(3):290-3.

23. Ayer V, Tewodros W, Manoharan A, Skariah S, Luo F, et al. Tetracycline Resistance in Group A Streptococci: Emergence on a Global Scale and Influence on Multiple-Drug Resistance. Antimicrob Agents Chemother. 2007;51(5):1865-8

24. Brahmadathan KN, Anitha P, Gladstone P. Increasing erythromycin resistance among Group A Streptococci causing tonsillitis in a tertiary care hospital in southern India. Clin Microbiol Infect. 2005;11:335-7.

25. Jecob SE, Lloyd CAC, Menon T. cMLS and M phenotypes among Streptococcus pyogenes in Chennai. Indian J Medi Microbiol. 2006;24:147-8

26. Ray D, Sinha S, Saha S, Karmakar S, Dutta RN, et al. A preliminary sentinel surveillance report on antibiotics resistance trend of Streptococcus pyogenes in Kolkata region, India. Al Ameen J Med Sci. 2010;3(2):146-51.

27. McCormick JK, Tripp TJ, Olmsted SB, Matsuka YV, Gahr PJ, et al. Development of Streptococcal pyrogenic exotoxin C Vaccine toxoids that are protective in the rabbit model of toxic shock syndrome. J Immunol. 2000;165:2306-12

28. Ryan PA, Juncosa B. Group A Streptococcal Adherence. In: Ferretti JJ, Stevens DL, Fischetti VA, editors. Streptococcus pyogenes: Basic Biology to Clinical Manifestations. Oklahoma City: University of Oklahoma Health Sciences Center; 2016.

29. Stanley J, Linton D, Desai M, Efstratiou A, George R. Molecular Subtyping of Prevalent M Serotypes of Streptococcus pyogenes Causing Invasive Disease. J Clin Microbiol. 1995:3:2850-5.

30. Podbielski A, Melzer B, Lutticken E. Application of the polymerase chain reaction to study the $\mathrm{M}$ protein (-like) gene family in beta-hemolytic Streptococci. Med Microbiol Immunol. 1991;180:213-27.

31. Vlaminckx BJM, Mascini EM, Schellekens J, Schouls LM, Paauw A, et al. Site-Specific Manifestations of Invasive Group A Streptococcal Disease: Type Distribution and Corresponding Patterns of Virulence Determinants. J Clin Microbiol. 2003;41:4941-9.

32. National Committee for Clinical Laboratory Standards. Performance standards for antimicrobial susceptibility testing; ninth informational supplement. Document M100-S9. NCCLS, Wayne, Pennsyslvania: CLSI; 1999. 19(1): Table 2l.

33. Clinical and Laboratory Standards Institute. Performance standards for antimicrobial susceptibility testing; 15th informational supplement, CLSI/NCCLS M100-S15. Wayne: Clinical and Laboratory Standards Institute; 2012.

34. Kumar R, Vohra H, Chakraborty A, Sharma YP, Bandhopadhya S, et al. Epidemiology of Group A Streptococcal pharyngitis \& impetigo: A cross-sectional \& follow up study in a rural community of Northern India. Ind J Med Res. 2009;130:765-71.

35. Dhanda V, Vohra H, Kumar R. Virulence potential of Group A streptococci isolated from throat cultures of children from north India. Indian J Med Res. 2011;133:674-80

36. Meisal R, Hoiby EA, Aaberge IS, Caugant DA. Sequence Type and emm-Type Diversity in Streptococcus pyogenes Isolates Causing Invasive Disease in Norway between 1988 and 2003. J Clin Microbiol. 2008;46(6):2102-5.
37. Mathur P, Bhardwaj N, Gupta G, Punia P, Tak V, et al. Outbreak of Streptococcus pyogenes emm type 58 in a high dependency unit of a level-1 trauma center of India. Indian J Crit Care Med. 2014;18(2):77-82.

38. Musser JM, Gray BM, Schlievert PM, Pichichero ME. Streptococcus pyogenes Pharyngitis: Characterization of Strains by Multilocus Enzyme Genotype, $\mathrm{M}$ and T Protein Serotype, and Pyrogenic Exotoxin Gene Probing. J Clin Microbiol. 1992;30:600-3.

39. O'Brien KL, Beall B, Barrett NL, Cieslak PR, Reingold A, et al. Epidemiology of invasive Group A Streptococcus disease in the United States, 1995-1999. Clin Infect Dis. 2002;35:268-76.

40. Durmaz R, Durmaz B, Bayraktar M, Ozerol IH, Kalcioglu MT, et al. Prevalence of Group A Streptococcal Carriers in Asymptomatic Children and Clonal Relatedness among Isolates in Malatya, Turkey. J Clin Microbiol. 2003;41:5285-7.

41. Tamayo E, Montes M, Garcia-Arenzana JM, Perez-Trallero E. Streptococcus pyogenes emm-types in northern Spain; population dynamics over a 7-year period. J Infect. 2014;68(1):50-7.

42. Harari BL, Straut M, Cretoiu S, Surdeanu M, Ungureanu V, et al. Molecula characterization of invasive and noninvasive Streptococcus pyogenes isolates from Romania. J Med Microbiol. 2008:57:1354-63.

43. Nandi S, Chakraborti A, Bakshi DK, Rani A, Kumar R, et al. Association of pyrogenic exotoxin genes with pharyngitis and rheumatic fever/rheumatic heart disease among Indian isolates of Streptococcus pyogenes. Lett Appl Microbiol. 2002:35(3):237-41.

44. Detcheva A, Facklam RR, Beall B. Erythromycin-Resistant Group A Streptococcal Isolates Recovered in Sofia, Bulgaria, from 1995 to 2001. J Clin Microbiol. 2002;40:3831-4.

45. Bahnan W, Hashwa F, Araj G, Tokajian S. emm typing, antibiotic resistance and PFGE analysis of Streptococcus pyogenes in Lebanon. J Med Microbiol. 2011;60:98-101.

46. Shackcloth J, Williams L, Farrell DJ. Streptococcus pneumoniae and Streptococcus pyogenes isolated from a paediatric population in Great Britain and Ireland: the in vitro activity of telithromcycin versus comparators. J Infect. 2004;48(3):229-35

47. Brown SD, Rybak MJ. Antimicrobial susceptibility of Streptococcus pneumoniae, Streptococcus pyogenes and Haemophilus influenzae collected from patients across the USA, in 2001-2002, as part of the PROTEKT US study. J Ant Chemother. 2004;54:i7-i15.

48. Erdem G, Ford J, Johnsin D, Abe L, Yamaga K, et al. Erythromycin-resistant Group A Streptococcal isolates collected between 2000 and 2005 in Oahu, Hawaii, and their emm types. J Clin Microbiol. 2005:43(5):2497-9.

49. Shibl AM. Patterns of macrolide resistance determinants among S.pyogenes and S. pneumoniae isolates in Saudi Arabia. J Int Med Res. 2005;33(3):349-55.

50. Ibrahim SB, Sokkary RHE, Elhewala AA, Anwar MWE, Awad MW, et al. Emerging Resistance to Erythromycin and Penicillin among Streptococcus pyogenes Isolates in Zagazig, Egypt. Int J Curr Microbiol App Sci. 2014;3(10):750-6.

51. Takahashi T, Arai K, Lee DH, Koh EH, Yoshida H, Yano H, et al. Epidemiological Study of Erythromycin-Resistant Streptococcus pyogenes From Korea and Japan by emm Genotyping and Multilocus Sequence Typing. Ann Lab Med. 2016:36(1):9-14.

52. Green MD, Beall B, Marcon MJ, Allen CH, Bradley JS, Dashefsky B, et al. Multicentre surveillance of the prevalence and molecular epidemiology of macrolide resistance among pharyngeal isolates of group A streptococci in the USA. J Antimicrob Chemother. 2006:57:1240-3.

53. Chen I, Kaufisi P, Erdem G. Emergence of erythromycin-and clindamycin resistant Streptococcus pyogenes emm90 strains in Hawaii. J Clin Microbiol. 2011;49(1):439-41.

54. Grivea IN, Al-Lahham A, Katopodis GD, Syrogiannopoulos GA, Reinert RR. Resistance to Erythromycin and Telithromycin inStreptococcus pyogenes Isolates Obtained between 1999 and 2002 from Greek Children with Tonsillopharyngitis: Phenotypic and Genotypic Analysis. Antimicrob Agents Chemother. 2006;50(1):256-61.

55. Tamayo J, Trallero JEP, Garces JLG, Alos Jl, on behalf of the Spanish Group for the Study of Infection in the Primary Health Care Setting (IAP-SEIMC). Resistance to macrolides, clindamycin and telithromycin in Streptococcus pyogenes isolated in Spain during 2004. J Antimicrob Chemother. 2005;56:780-2.

56. Jasir A, Tanna A, Noorani A, Mirsalehian A, Efstratiou A, et al. High Rate of Tetracycline Resistance in Streptococcus pyogenes in Iran: an Epidemiological Study. J Clin Microbiol. 2000;38:2103-7.

57. Liang Y, Liu X, Chang H, Ji L, Huang G, et al. Epidemiological and molecular characteristics of clinical isolates of Streptococcus pyogenes collected between 2005 and 2008 from Chinese children. J Med Microbiol. 2012;61:975-83. 
58. Rivera A, Rebollo M, Miro E, Mateo M, Navarro F. Superantigen gene profile, emm type and antibiotic resistance genes among Group A Streptococcal isolates from Barcelona, Spain. J Med Microbiol. 2006;55:1115-23.

59. Hraoui M, Boubaker IBB, Doloy A, Redjeb SB, Bouvet A. Molecular mechanisms of tetracycline and macrolide resistance and emm characterization of Streptococcus pyogenes isolates in Tunisia. Microb Drug Resist. 2011;17(3):377-82

Submit your next manuscript to BioMed Central and we will help you at every step:

- We accept pre-submission inquiries

- Our selector tool helps you to find the most relevant journal

- We provide round the clock customer support

- Convenient online submission

- Thorough peer review

- Inclusion in PubMed and all major indexing services

- Maximum visibility for your research

Submit your manuscript at www.biomedcentral.com/submit
Biomed Central 